\title{
Suchaufruf für Martin Buber-Werkausgabe
}

Der Verlag Lambert Schneider, jetzt in D-70839 Gerlingen bei Stuttgart, der die Schriften Martin Bubers (1878-1965) seit 1925 verlegerisch betreut, bereitet eine auf 22 Bände angelegte, umfassende Werkausgabe des bedeutenden jüdischen Religionsphilosophen, Bibelübersetzers und Vermittlers der chassidischen Traditionen vor. Den eigentlichen Werken des universalen Gelehrten, der seit 1923 zunächst Lehrbeauftragter für jüdische Religionswissenschaft und jüdische Ethik, sodann von 1930-1933 Honorarprofessor für Religionswissenschaft an der Universität Frankfurt am Main war und seit 1938 eine Professur für Sozialphilosophie an der Hebräischen Universität Jerusalem innehatte, sollen in zwei weiteren Abteilungen auch die Bibelverdeutschung und - in größtmöglichem Umfang - das Briefwerk angegliedert werden. Geschäftsführende Herausgeber dieser ersten umfassenden Werkausgabe sind Professor Dr. Paul Mendes-Flohr von der Hebräischen Universität Jerusalem und Professor Dr. Willy Schottroff von der Johann Wolfgang Goethe-Universität Frankfurt am Main.

Für die Erarbeitung der Werkausgabe wird eine vollständige Erfassung aller hinterlassenen Äußerungen Bubers erstrebt, auch die von Lebenszeugnissen, Bildern, Gesprächsaufzeichnungen, Interviews etc. Die Herausgeber bitten Personen, Archive, Institutionen, die sich im Besitz einschlägiger Materialien befinden, dies mitzuteilen und nach Möglichkeit Kopien dieser Dokumente zu senden an:

Prof. Dr. Willy Schottroff

Im Rosental 6

D-34132 Kassel. 